\title{
An Unusual Cause of Colon Polyps
}

\section{W. Bohle, W. G. Zoller}

Department of Gastroenterology, Katharinenhospital Stuttgart, Stuttgart, Germany

\section{Corresponding Author}

\section{W. Bohle, M.D.}

Department of Gastroenterology Katharinenhospital Stuttgart

Kriegsbergstrasse 60

70174 Stuttgart

\section{Germany}

Fax:

+ 49-711-2785401

E-mail: W.Bohle@katharinenhospital.de

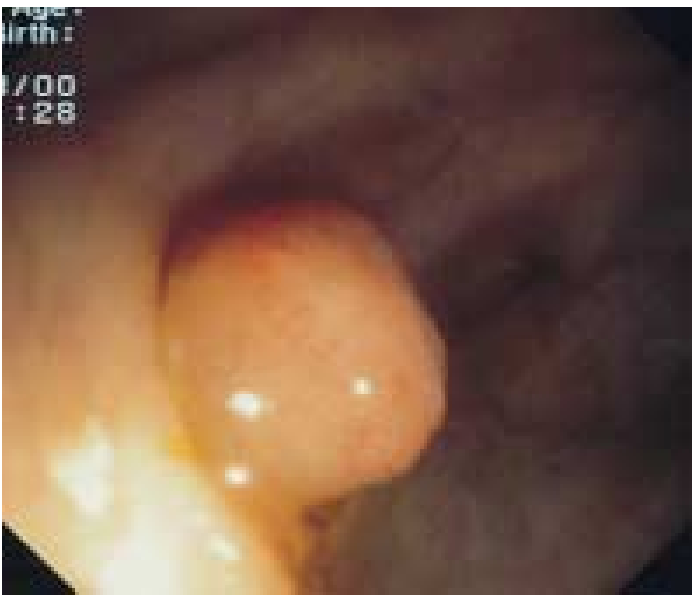

Figure 1 An 81-year-old man presenting with general weakness and anemia, underwent colonoscopy because of a positive hemoccult test. During the examination, several small, sometimes centrally eroded polyps, measuring 6-8 $\mathrm{mm}$ in diameter, were found.

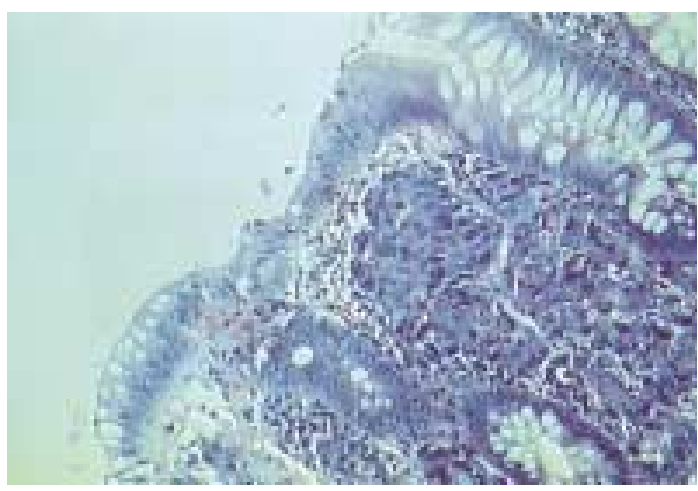

Figure 2 Histological analysis revealed submucosal metastatic spread of an adenocarcinoma, incompletely covered by normal mucosa. Gastroscopy revealed an adenosquamous carcinoma of the esophagogastric junction to be the primary tumor. The patient refused further treatment and died several weeks later. 